LA GARANTIA CONSTITUCIONAL DE LAAUTONOMÍA UNIVERSITARIA: LEGITIMIDACD EN POEÍTICAS PÚBLICAS EDUCATIVAS EN EL ESTADO SOCIALDE DERECHO EN COLOMBIA

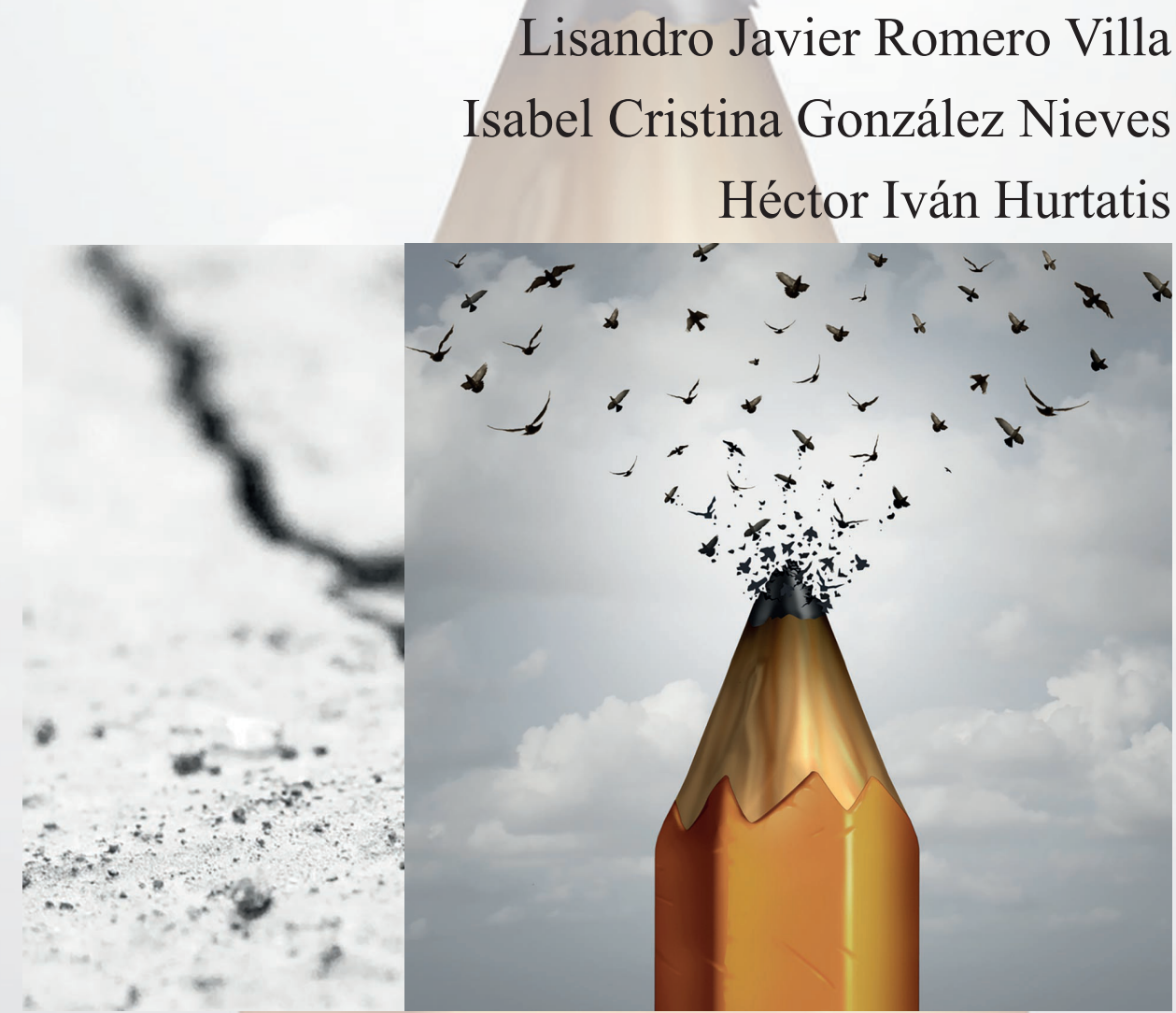





\title{
LA GARANTÍA CONSTITUCIONAL DE LA AUTONOMÍA UNIVERSITARIA: LEGITIMIDAD EN POLÍTICAS PÚBLICAS EDUCATIVAS EN EL ESTADO SOCIAL DE DERECHO EN COLOMBIA*
}

\author{
Lisandro JaVier Romero Villa \\ Isabel Cristina GonZález Nieves \\ HÉCTOR IVÁn Hurtatis \\ Universidad Católica de Colombia \\ Universidad de Buenos Aires
}

\section{Resumen}

Desde la Constitución Política de 1991, la autonomía universitaria ha desempeñado un importante rol en las principales políticas públicas educativas, los planes de desarrollo nacionales y los precedentes jurisprudenciales de la materia. En el presente artículo se analiza el alcance de la autonomía universitaria frente a la acción efectiva de políticas públicas de educación superior en Colombia a partir de la Ley 30 de 1992 y del Artículo 69 de la Constitución Política de Colombia y se aborda la manera como este principio constitucional es trazable en la materialización de las políticas de educación superior y en los retos para su desarrollo.

Palabras clave: autonomía universitaria, educación, políticas públicas, estado social de derecho.

Los autores: Lisandro Javier Romero Villa, profesor de la Universidad Católica de Colombia.

Isabel Cristina Gonzáles Nieves, profesora de carrera de la Universidad de Buenos Aires.correo electrónico: gonzaleznieves@derecho.uba.ar

Héctor Iván Hurtatis, politólogo y magíster en Política Pública. Correo electrónico: ivanhurtatis@gmail.com

Recibido: 13 de octubre de 2017; evaluado: 4 de febrero de 2018; aceptado: 23 de agosto de 2018.

Artículo de reflexión que forma parte de un avance de investigación del proyecto de tesis doctoral "La autonomía universitaria, una garantía constitucional frente a la acción efectiva de las políticas públicas en materia de educación superior", para la Universidad de Buenos Aires. 


\title{
THE CONSTITUTIONAL GUARANTEE OF THE UNIVERSITY AUTONOMY: EDUCATIONAL POLICIES LEGITIMACY IN THE SOCIAL STATE OF LAW IN COLOMBIA
}

\author{
Lisandro JaVier Romero Villa \\ Isabel Cristina GonZÁlez Nieves \\ HÉCTOR IVÁN HuRTATIS \\ Universidad Católica de Colombia \\ Universidad de Buenos Aires
}

\begin{abstract}
Since the Political Constitution of 1991, university autonomy has played an important role in the main education policies, in national development plans, as well as in jurisprudential precedents about the topic. This article analyzes the scope of university autonomy regarding the effective action of public higher education policies in Colombia according to the Law 30 of 1992 and the article 69 of the Colombian Political Constitution, addressing the way how this constitutional principle is traceable in higher education policies and its developmental challenges.
\end{abstract}

Keywords: university autonomy, education, public policies, welfare State.

About the authors: Lizandro Javier Romero Villa, Professor at the Universidad Católica de Colombia. Isabel Cristina González Nieves, email: gonzaleznieves@derecho.uba.ar

Héctor Iván Hurtatis, political scientist and MA in Public Policy. Email: ivanhurtatis@gmail.com

Received: October 13, 2017; reviewed: Febrery 4, 2018; accepted: August 23, 2018

Reflection article that forms part of the PhD dissertation project "University autonomy, a constitutional guarantee against the effective action of public policies in higher education," at the Universidad de Buenos Aires. 


\section{Introducción: autonomía universitaria, antecedentes y nuevas aproximaciones dentro de la gobernanza}

El concepto de la autonomía universitaria data de la Edad Media, desde la Universidad de Bolonia en el año 1087. ${ }^{1}$ Para la época, los estudiantes de Bolonia eran considerados extranjeros en dicha ciudad y, por ende, el ejercicio de sus derechos resultaba muy limitado, a la vez que eran víctimas de abusos como la confiscación de sus bienes y el aumento de impuestos y rentas en alimentos y vivienda, entre otras formas que impedían un adecuado ejercicio académico. ${ }^{2}$ Por ello, la comunidad académica decidió forjar un gremio para solicitar colectivamente el apoyo de las autoridades administrativas y políticas que les garantizara protección mediante un amparo jurídico. Esta consideración fue asumida por el emperador Federico Barbarroja, quien garantizó al gremio la protección y autonomía, para evitar la injerencia de factores políticos o económicos en el desarrollo académico.

Situación similar sucedió con la Universidad de París, también durante la Edad Media. Debido al creciente número de profesores de filosofía, el Obispado de París "otorgaba una licencia para la enseñanza, llamada licentia docendi. Esta licencia garantizaba a los escolares que su profesor podía formarlos adecuadamente para iniciar o proseguir una carrera clerical". ${ }^{3}$ Los maestros formaron un gremio para admitir a quienes eran sus colegas, pero no contaban con la mencionada licencia; para lograrlo, también buscaron la protección de una autoridad superior que, en este caso, fue el Papa, quien apoyó al gremio y otorgó cierto margen de autonomía en el desarrollo académico.

En el siglo XIX se vivió una enorme renovación del concepto, sobre todo en Berlín, donde la universidad determinó importantes revoluciones epistemológicas a partir del empirismo y del positivismo. Se determinó que el método científico debía emplearse en plena libertad tanto presupuestal como de pensamiento, lo cual conllevó a que los Estados garantizaran autonomía académica y apoyo económico para potenciar los avances científicos.

Armando Pavón Romero y Clara Inés Ramírez, "La autonomía universitaria, una historia de siglos", La autonomía universitaria, una historia de siglos 1, núm. 1 (mayo, 2010): 157, https://www.ries.universia.unam. mx/index.php/ries/article/view/22/84 (acceso agosto 5, 2018).

2 Pavón Romero y Ramírez, "La autonomía universitaria, una historia de siglos", 157.

3 Eduardo Cerebeiros Álvarez, "La licentia docendi: comienzo y desarrollo de la carrera universitaria", Repositorio Universidade Coruña, núm. 8 (2004): 158, https://ruc.udc.es/dspace/bitstream/handle/2183/2316/AD-8-15. pdf?sequence=1\&isAllowed =y (acceso agosto 5, 2018). 
Con la crisis económica de 1929 y el surgimiento de las ideas keynesianas ${ }^{4}$ sobre la intervención del Estado en la economía nacional se impulsaron importantes reformas al Estado liberal clásico basadas en precedentes como la Constitución de Weimar en Alemania, Tlatelolco en México y el New Deal de Roosevelt en Estados Unidos a inicios del siglo XX. Ahí se fundamentaron los principios del Estado social de derecho o welfare State, que sustentan la teoría organizativa estatal para tomar decisiones legales y constitucionales que priorizaran la dignidad humana y los derechos fundamentales de los asociados y establecer políticas que aliviaran la pobreza y el desempleo por medio de grandes recaudaciones tributarias, ahorro, planeación macroeconómica e inversión social, tras corregir las naturales fallas del sistema de mercado. ${ }^{5}$

El referente de un Estado social de derecho se relaciona con la necesidad de garantizar una educación pública, gratuita y de calidad, en tanto es una inversión necesaria para el adecuado cumplimiento de los fines del Estado. Desde ese entendido, la educación comprendería dos fines específicos: el desarrollo de capacidades técnicas e intelectuales de la sociedad para su vinculación al mundo laboral y estimular el desarrollo de capacidades analíticas, reflexivas y propositivas que permitan formular las grandes preguntas y respuestas a las necesidades sociales del país.

Con la influencia del paradigma de la nueva gestión pública y el desarrollo del consenso de Washington, la educación se adecuó como un servicio sujeto a la demanda y oferta del libre mercado; la intervención del Estado se limitaba a la vigilancia, al monitoreo y a la supervisión de los lineamientos expuestos por la ley. A pesar de las limitaciones que tuvo este enfoque, el Estado colombiano mantuvo un rol protagónico en los lineamientos y requerimientos que garantizaran la calidad educativa, sin perjuicio de los aspectos fundamentales de la autonomía universitaria. Esto se demuestra con las leyes y los decretos reglamentarios ya mencionados, que imponían unas exigencias legales a las instituciones de educación superior para determinar los estándares de calidad y ejercer mayor control y reglamentación oficial.

En los últimos años, el ingreso de Colombia a la Organización para la cooperación y el desarrollo económicos (OCDE) ha supuesto una dinámica mucho más participativa que involucra actores de diversas corrientes epistemológicas, para diseñar estrategias que abarquen autonomía universitaria y calidad y proveer un servicio a la altura de una economía emergente y competitiva en una economía globalizada. Para la

John Keynes, El fin del dejar hacer (Madrid: Ariel, 1970), 58.

Ricardo Petrella, Los limites de la competitividad (Buenos Aires: Sudamericana, 1996), 229. 
OCDE, el rol de la educación superior resulta cada vez más importante, puesto que la productividad está directamente correlacionada con la productividad y el crecimiento económico y que la innovación es el principal objetivo en el desarrollo del capital humano. ${ }^{6}$

La educación superior contribuye en ambas metas y además a la cohesión social, entendida como la voluntad de los ciudadanos para cooperar en un ambiente social, cultural e incluso ambiental en el progreso de las sociedades. Para la OCDE, la educación y la orientación estatal en términos de calidad y autonomía universitaria son esenciales para fomentar capacidades técnicas, profesionales y específicas de conocimiento; son también relevantes si se articulan con industrias de conocimiento y servicio que promuevan la productividad y los procesos tecnológicos que se destaquen en la formulación de patentes y otros instrumentos que estimulen la propiedad intelectual y la innovación científica.

Como se observa, las inversiones de los Estados modernos en educación superior no solo buscan garantizar unos derechos básicos en términos de equidad, acceso y calidad; la tendencia actual evidencia que son destinaciones presupuestales estratégicas que traerán un alto valor agregado en el desarrollo económico y en las capacidades ciudadanas para el fomento de capital social.

La evolución del concepto de autonomía universitaria y calidad está relacionada con la importancia estratégica que los Estados modernos les dieron a la financiación y a la vigilancia de los centros universitarios. A pesar de las modificaciones que se han hecho, varios aspectos sobre la autonomía universitaria siguen vigentes en el centro del debate para señalar sus límites y grados de materialización en las políticas públicas, como se verá a continuación.

\section{Autonomía universitaria y calidad como conceptos articulados desde la Constitución y la ley}

La Constitución Política de Colombia consagra en el Artículo 69 la garantía de la autonomía universitaria ${ }^{7}$ como un elemento imprescindible de los procesos de

\footnotetext{
Organización para la cooperación y el desarrollo económicos [OCDE], Report on Benchmarking Higher Education System Performance: Conceptual Framework and Data (París: Autor, 2017), 9.

7 "Se garantiza la autonomía universitaria. Las universidades podrán darse sus directivas y regirse por sus propios estatutos, de acuerdo con la ley. La ley establecerá un régimen especial para las universidades del Estado. El Estado fortalecerá la investigación científica en las universidades oficiales y privadas y ofrecerá
} 
educación superior en condiciones óptimas, de modo que sean más democráticos, transparentes, efectivos, constructivos, eficientes y pluralistas. La autonomía es un principio que constituye la base del campo de acción de las políticas públicas de educación superior, porque fija un límite más amplio de las intervenciones estatales, al moldear y configurar su naturaleza. La Corte Constitucional señaló que el "sentido" de la autonomía universitaria es "asegurar la misión de la universidad"; en otras palabras, la materialización de los deseos de descentralización de las cargas de las instituciones de educación superior, con el fin de ofrecer una educación con parámetros de calidad. Este punto resulta relevante porque se entabla una relación entre autonomía y calidad:

Prestar a la comunidad un servicio con calidad, el cual hace referencia a los resultados académicos, a los medios y procesos empleados, a la infraestructura institucional, a las dimensiones cualitativas y cuantitativas del mismo y a las condiciones en que se desarrolla cada institución. ${ }^{10}$

En consonancia con esa relación, la conceptualización abordada puede verse desde dos perspectivas: una definición de calidad educativa abierta y normativa, entendida como "aquella que forma mejores seres humanos, ciudadanos con valores éticos, respetuosos de lo público, que ejercen los derechos humanos y conviven en paz. Una educación que genera oportunidades legítimas de progreso y prosperidad para ellos y para el país". ${ }^{11}$ Esta aproximación denota un amplio objetivo que puntualiza a las instituciones de educación superior como un lugar para la creación científica y de conocimiento técnico y como eje para la construcción de ciudadanía activa en el desarrollo social.

La segunda definición es cerrada y específica. Se entiende la calidad como un concepto multidimensional que articula procesos de admisión de los estudiantes; alcance de metas en términos cualitativos y cuantitativos a partir de la gestión de resultados; capacidad de infraestructura física, administrativa y académica, entre otros requerimientos concretos. Esto quiere decir que la calidad supone el esfuerzo

las condiciones especiales para su desarrollo. El Estado facilitará mecanismos financieros que hagan posible el acceso de todas las personas aptas a la educación superior". República de Colombia, Constitución Política (Bogotá: Legis, 1991), art. 69.

8 Colombia, Corte Constitucional, Sentencia T-574 de 10 de diciembre de 1993, M. P. Eduardo Cifuentes Muñoz.

9 Colombia, Corte Constitucional, Sentencia T-574 de 10 de diciembre de 1993.

10 Congreso de la República de Colombia, Ley 30 de 1992, "Por la cual se organiza el servicio público de la Educación Superior" (Bogotá: Diario Oficial No. 40.700, 19 de diciembre de 1992), art. 6.

11 Ministerio de Educación Nacional, Educación de calidad, el camino para la prosperidad (Bogotá: Autor, 2016), 12 . 
continuo de las instituciones para cumplir de forma responsable con las exigencias propias de cada una de sus funciones, como la docencia, la investigación y la proyección social. ${ }^{12}$

El Ministerio de Educación ha establecido unos objetivos específicos que permiten alcanzar la calidad de la oferta de educación superior en el país, que incluye propiciar una cultura de evaluación y autoevaluación permanente y sistemática encaminada al mejoramiento; afianzar la pertinencia, la cobertura y la equidad de la educación superior; fomentar la atención integral de los estudiantes y demás actores de la comunidad académica, con los servicios del sistema y consolidar una mayor transparencia en la gestión institucional.

A partir de la Ley 30 de 1992 se definieron los lineamientos para el funcionamiento del Sistema de aseguramiento de la calidad de la educación superior, el cual se reglamentó por medio del Decreto 2566 de 2003 con quince condiciones mínimas de calidad que constituían un requisito obligatorio para todo programa académico que se ofreciera en Colombia. Así, las universidades están sujetas a un registro calificado, reglamentado por la Ley 1188 de 2008, que se constata mediante un proceso de evaluación y verificación, manejado por la Comisión nacional intersectorial para el aseguramiento de la calidad de la educación superior (Conaces).

En el proceso de diseño y ejecución de las políticas públicas de educación superior, la autonomía universitaria se articula con la calidad, pues las universidades desarrollan su proyección educativa a partir de su libertad para trazar metas y parámetros, sin perjuicio del cumplimiento de los requerimientos del Sistema nacional de acreditación de calidad para la educación superior.

La autonomía universitaria consagrada en la Constitución Política de Colombia y de conformidad con la presente Ley, reconoce a las universidades el derecho a darse y modificar sus estatutos, designar sus autoridades académicas y administrativas, crear, organizar y desarrollar sus programas académicos, definir y organizar sus labores formativas, académicas, docentes, científicas y culturales, otorgar los títulos correspondientes, seleccionar a sus profesores, admitir a sus alumnos y adoptar sus correspondientes regímenes y establecer,

12 Consejo Nacional de Acreditación, “QQué significa calidad en la educación superior? ¿Cómo se determina?”, https://www.cna.gov.co/1741/article-187264.html (acceso septiembre 1, 2018). 
arbitrar y aplicar sus recursos para el cumplimiento de su misión social y de su función institucional. ${ }^{13}$

El artículo agrega que el Estado garantizará la autonomía universitaria y velará por la calidad del servicio educativo mediante la inspección y la vigilancia y dará la libertad a las universidades para determinar estatutos, régimen interno, programas, presupuesto y planes de estudio, entre otros.

A pesar de la claridad con la que se relacionan la autonomía universitaria y la calidad, el Constituyente no otorgó una autonomía absoluta, en tanto fija otros límites que permitan garantizar la inspección y la vigilancia sobre la educación atribuidas al Estado, para cumplir con los fines deseados de la educación superior, en particular sobre la calidad. Aquí se abre un importante punto de discusión, puesto que la definición del límite que supone la intervención del Estado en las instituciones educativas es un tema que involucra a diversos actores, cuyos intereses e interpretaciones moldean los puntos de vista y enfoques de la discusión.

En los últimos años, algunas universidades públicas han sido cooptadas por intereses regionales, pues los centros académicos pasan a convertirse en botines de actores políticos para favorecer el clientelismo. Por otra parte, diversas universidades han sido permeadas por células de organizaciones violentas que la convierten en territorio de guerra en disputa con otros grupos armados de la misma índole; en algunos casos pesa bastante la ausencia de controles efectivos del Estado, sobre todo en cuanto a destinación presupuestal y se ha denunciado que los centros universitarios se ven impedidos para cumplir sus funciones a cabalidad debido a la crisis financiera que ha dejado, a 2018, un déficit fiscal de casi \$ 434.874.000. ${ }^{14}$

Todo este escenario posibilita los mencionados debates para entender hasta qué punto se puede propender por la vigilancia y el control de las universidades, sin violar los preceptos de autonomía que les otorga la constitución política.

En temáticas de autonomía universitaria se destacan la importancia de la evolución jurisprudencial constitucional y el análisis que se ha venido haciendo sobre la norma y las reglas de la equidad y justicia. Fassó expresa que esta relación depende por completo del estado particular o de la condición en la que se encuentran las

Congreso de la República de Colombia, Ley 30 de 1992, art. 28.

14 Universidad Distrital Francisco José de Caldas, "Panel: La crisis de las universidades públicas en Colombia", https://www.udistrital.edu.co/panel-crisis-las-universidades-publicas-en-colombia (acceso agosto 1, 2018). 
personas y deben su origen y existencia a la utilidad que de su estricta y regular observancia deriva al público. ${ }^{15}$

\section{La educación en Colombia y su enfoque hacia la autonomía universitaria}

En Colombia, el Estado reconoce y protege la diversidad étnica y cultural de la Nación ${ }^{16}$ y garantiza las libertades de enseñanza, aprendizaje, investigación y cátedra. ${ }^{17}$ La educación es un derecho de la persona y un servicio público que tiene una función social, con el que se busca acceso al conocimiento, a la ciencia, a la técnica y a los demás bienes y valores de la cultura. ${ }^{18}$

El Estado, la sociedad y la familia son responsables de la educación y corresponde al primero regular y ejercer la suprema inspección y vigilancia de esta, con el fin de velar por la calidad, el cumplimiento de sus fines y la mejor formación moral, intelectual y física de los educandos, así como garantizar el adecuado cubrimiento del servicio y asegurar a los menores las condiciones necesarias para su acceso y permanencia en el sistema educativo.

Así las cosas, la Nación y las entidades territoriales participarán en la dirección, financiación y administración de los servicios educativos estatales en los términos que señalen la Constitución y la ley. En esta línea del Estado social de derecho y de la necesidad de garantizar una educación de calidad se orientan algunos de los objetivos de la Ley 30 de 1992:

a) Profundizar en la formación integral de los colombianos en las modalidades y calidades de la educación superior y capacitarlos para cumplir las funciones profesionales, investigativas y de servicio social que requiere el país.

b) Trabajar por la creación, el desarrollo y la transmisión del conocimiento en todas sus formas y expresiones y, promover su utilización en todos los campos para solucionar las necesidades del país.

15 Guido Fassó, Historia de la filosofía del derecho, tomo 2: La Edad Moderna, trad. José F. Lorca Navarrete (Madrid: Pirámide SA, 1982), 216.

16 República de Colombia, Constitución Política, art. 8.

17 República de Colombia, Constitución Política, art. 27.

18 República de Colombia, Constitución Política, art. 67. 
c) Prestar a la comunidad un servicio con calidad, el cual hace referencia a los resultados académicos, a los medios, a los procesos desarrollados, a la infraestructura institucional, a sus dimensiones cualitativas y cuantitativas y a las condiciones de cada institución.

Por medio de la Sentencia T-002 de 1992, la Corte Constitucional declaró a la educación como un servicio público y señaló:

La educación es un derecho de la persona y un servicio público que tiene una función social; con ella se busca el acceso al conocimiento, a la ciencia, a la técnica, y a los demás bienes y valores de la cultura. La educación formará al colombiano en el respeto a los derechos humanos, a la paz y a la democracia; y en la práctica del trabajo y la recreación, para el mejoramiento cultural, científico, tecnológico y para la protección del ambiente [... ]. Corresponde al Estado regular y ejercer la suprema inspección y vigilancia de la educación con el fin de velar por su calidad, por el cumplimiento de sus fines y por la mejor formación moral, intelectual y física de los educandos; garantizar el adecuado cubrimiento del servicio y asegurar a los menores las condiciones necesarias para su acceso y permanencia en el sistema educativo. La Nación y las entidades territoriales participarán en la dirección, financiación y administración de los servicios educativos estatales, en los términos que señalen la Constitución y la ley. ${ }^{19}$

La Corte expresó también:

Por lo que respecta a la educación superior, el artículo 69 de la Constitución garantiza la autonomía universitaria, la cual encuentra fundamento en la necesidad de que el acceso a la formación académica de las personas tenga lugar dentro de un clima libre de interferencias del poder público tanto en el campo netamente académico como en la orientación ideológica, o en el manejo administrativo o financiero del ente educativo $\left[\ldots . .{ }^{20}\right.$

El concepto de autonomía universitaria implica la consagración de una regla general que consiste en la libertad de acción de los centros educativos superiores, de tal

19 Colombia, Corte Constitucional, Sentencia T-002 de 8 de mayo de 1992, M. P. Alejandro Martínez Caballero.

20 Colombia, Corte Constitucional, Sentencia T-492 de 2 de mayo de 1992, M. P. José Gregorio Hernández Galindo. 
modo que las restricciones sean excepcionales y estén previstas en la ley, según lo establece con claridad el Artículo 69 de la Constitución Política.

Desde un enfoque de política pública se puede apreciar que la autonomía universitaria ha desempeñado un rol importante en la apuesta del Plan nacional decenal de educación (PNDE) (2006-2016) por la calidad articulada al principio de la autonomía universitaria.

En dicha política se estipulan importantes lineamientos en materia de pautas curriculares para grados y títulos, sistema de niveles y grados, atención a todo tipo de poblaciones, políticas generales prioritarias, ampliación de cobertura, fortalecimiento de la institución escolar, descentralización de la educación, financiación, evaluación y, en general, acciones desarrolladas por el sector educativo en todas sus áreas y disciplinas.

En resumen, con estas iniciativas y disposiciones se mantiene la orientación a trabajar entre el Estado y las universidades en estrategias conjuntas proyectadas al mejoramiento de la calidad del servicio educativo, en la perspectiva de Estado social de derecho y con prevalencia de la dignidad humana y del respeto, del reconocimiento, de la garantía y la protección de los derechos.

La política pública garantiza a las universidades el ejercicio de su autonomía en los siguientes temas: sus estatutos; su régimen interno; los mecanismos referentes a elección, designación y períodos de sus directivos; las reglas sobre selección y nominación de profesores; programas de su desarrollo; presupuesto y planes de estudio.

En síntesis, el concepto de la autonomía universitaria consagra una libertad de acción de los centros educativos superiores enmarcada en limitaciones previstas por la ley.

\section{Pronunciamientos de sentencias constitucionales respecto a las controversias sobre la autonomía constitucional}

Conforme a la reiterada jurisprudencia de la Corte Constitucional (Sentencias C-544, C-587, T-503, T-406, T-596 de 1992, C-104 de 1993 y SU-111 de 1997), el Artículo 69 de la Constitución Política reconoce la autonomía universitaria como fundamento ideario de la libertad de enseñanza, de cátedra, de aprendizaje y de investigación, como lo expresara el profesor Eduardo García Enterría: "[... la la 
autonomía universitaria quiere decir, en primer término, libertad de los docentes para poner en cuestión la ciencia recibida, para investigar nuevas fronteras de lo cognoscible, para transmitir versiones propias de la ciencia". ${ }^{21}$

Este análisis de la autonomía universitaria, que no es exclusivo del Tribunal colombiano, tiene semejanza con las leyes orgánicas españolas, que también han discutido su naturaleza y la han asumido como una garantía constitucional o como un derecho fundamental en cuanto a sus consecuencias.

El Tribunal español coincide con la Corte Constitucional en cuanto a que el tratamiento como un derecho fundamental faculta a su titular para ejercer una determinada pretensión y, como garantía constitucional, no habilita para el ejercicio de derechos subjetivos, pero sirve para protegerlos, porque obliga al Legislador a respetar el núcleo de la institución garantizada. ${ }^{22}$

La autonomía es un atributo reconocido por el Estado, que adquiere el significado constitucional y dota a la universidad de poder para relacionarse con los poderes de este.

La literatura en la materia señala que la autonomía universitaria permite que la institución educativa determine su orden jurídico y establezca su organización, su funcionamiento y sus tipos de autoridad y, por lo tanto, para que se tomen decisiones libres sobre el desarrollo institucional y sobre los modos de vinculación con el marco social que rodea a la universidad.

En los últimos años, la autonomía ha evolucionado desde una concepción y aplicabilidad restringidas hacia un escenario de amplitud, aunque sigue limitada por ambigüedades normativas, políticas y de actores académicos.

A pesar de un importante número de normas y de decretos reglamentarios, se puede afirmar que no existe un límite normativo claro, lo que deja algunas zonas grises de interpretación que determinan la constante discusión de esta temática dentro del ambiente político y jurídico nacional, como se verá a continuación.

\footnotetext{
21 Eduardo García Enterría, "La autonomía universitaria", Revista de Administración Pública, núm. 117 (1988): 12.

22 Colombia, Corte Constitucional, Sentencia T-574 de 10 de diciembre de 1993.
} 


\section{Los retos y las acciones pendientes en el marco de la Ley 1740 de 2014}

La Ley 1740 de 2014 abre un nuevo interrogante sobre los límites de la inspección y la vigilancia que debe ejercer el Estado sin afectar la autonomía universitaria. Si bien la Ley 30 y el Artículo 69 de la Constitución Política definían parámetros específicos de autonomía universitaria, solo hasta 2014 se delimitaron los alcances de ese concepto, por medio de la Ley 1740 de ese año, que determina las normas de inspección y vigilancia de la educación superior en Colombia, en aras de preservar la calidad del servicio público. En ella se entiende a la educación en términos de continuidad, cubrimiento, cumplimiento de objetivos y rentas, entre otras particularidades.

En el Artículo 69, la autonomía universitaria se plantea en dos direcciones: una académica, en términos de notas y pensum y otra administrativa, que se basa en la capacidad de autodeterminación y autogestión organizativa de las universidades.

Algunas sentencias constitucionales ya habían señalado una jurisprudencia para advertir que la autonomía administrativa no es absoluta y es mucho más limitada que la académica, puesto que debido a su función social, sus funciones administrativas no dejaban de ser sujetos de control por parte de las autoridades.

La Ley 1740 de 2014, en sus Artículos 6 y 8, define la inspección como la facultad del Ministerio de Educación Nacional para solicitar, confirmar y analizar —en la forma, el detalle y los términos que determine- la información que requiera sobre la situación jurídica, contable, económica, administrativa o de calidad de cualquier institución de educación superior o sobre sus operaciones específicas. Además, entiende la vigilancia como la facultad del Ministerio de Educación Nacional de velar porque en las instituciones de educación superior se cumplan las normas para su funcionamiento, haya prestación continua del servicio público ajustado a la Constitución, la ley, los reglamentos y a sus propios estatutos en condiciones de calidad y supervise la implementación de correctivos de situaciones críticas de orden jurídico, económico, contable, administrativo o de calidad.

Los Artículos 7 y 9 fijan las siguientes funciones en materia de inspección y vigilancia:

1. Acceder a información de las instituciones de educación superior (IES). 
2. Solicitar reportes de información financiera.

3. Verificar la información que se ofrece al público para controlar y evitar los actos de publicidad engañosa.

4. Exigir estados financieros y requerir su rectificación.

5. Interrogar a cualquier persona de la institución o terceros relacionados.

6. Examinar y verificar la infraestructura institucional y las condiciones físicas en las que se desarrolla la actividad.

7. Solicitar informes atinentes a los recursos de la institución.

8. Averiguar y obtener información probatoria.

9. Hacer seguimiento a las actividades de las IES.

10. Hacer visitas generales o específicas y adoptar medidas para subsanar irregularidades.

11. Efectuar auditorías financieras y contables.

12. Dar trámite a las reclamaciones, con el fin de establecer responsabilidades administrativas o académicas.

13. Verificar que las actividades se ejecuten dentro de la ley, los reglamentos y los estatutos de la institución.

14. Solicitar rendición detallada de informes jurídicos, contables, financieros y administrativos.

15. Hacer acompañamiento para restablecer la continuidad del servicio o mejorar la calidad.

16. Conminar, bajo el apremio de multas hasta de 100 SMMLV, a directivos universitarios para que se abstengan de cometer actos contrarios a la ley o indebida destinación de recursos. 
La Ley 1740 aclara que, si bien las instituciones de educación superior del orden público no pertenecen a la Rama Ejecutiva ni están sometidas a control jerárquico y de tutelas, sí forman parte de la Administración pública y, por ende, sus actuaciones deben someterse a los preceptos públicos de contratación, gestión y administración, amparados en el principio de legalidad. No obstante, dicha Ley, abre un importante debate jurídico y político, porque las atribuciones que tiene el Ministerio de Educación se extienden a IES del orden privado.

En medio de las discusiones sobre la reforma a la educación superior, la Ley fue promulgada y, de hecho, sirvió para solucionar un problema que se presentó en la Fundación San Martín, lo que necesariamente ocasionó reacciones en ámbitos académicos, porque se consideró que el marco legal atentaba contra la autonomía de las universidades.

Varios actores, incluidos rectores y gremios de universidades privadas y públicas, señalan que la aprobación de la norma se hizo sin la participación de todos los implicados, lo que de entrada ofreció una dificultad, pues tal caso particular de intervención a una entidad de carácter privado originó una política pública generalizada que trascendía los límites que, por derecho propio, tenían las universidades de autogobernarse y gestionarse y se rompía con la autonomía universitaria.

Sin embargo, otros sectores como Ascún ven con buenos ojos estas intervenciones, puesto que permiten mejorar la calidad de las entidades universitarias, sin distingo de su razón pública o privada. Entre otras críticas, se advierte que: i) la Ley da igual tratamiento a dos sistemas educativos diferentes —el público y el privado— que, por su naturaleza y sus fines, precisan de un trato diferencial para comprender sus complejidades; ii) el Ministerio de Educación concentra bajo esta Ley dos funciones que deberían corresponder a distintos organismos; iii) al ser una política pública, hay un problema central en su diseño, pues nunca se consultó al sector educativo acerca de los contenidos de la Ley, y iv) las facultades excepcionales y exorbitantes atribuidas al Ministerio de Educación pueden constituir una amenaza real a la autonomía universitaria.

Hay otros sectores que están parcialmente de acuerdo con la postura propuesta por la Ley por las siguientes razones: i) la norma no afecta la autonomía universitaria, en tanto dicho concepto va acompañado de un control que el Estado debe ejercer; ii) la norma es un incentivo para fortalecer una sana competencia en la que los beneficiados sean los estudiantes, quienes pueden escoger, con mayor transparencia, 
la universidad donde desean estudiar; iii) las facultades especiales de inspección y vigilancia estipuladas por la ley son necesarias, puesto que garantizan estándares de calidad, eficiencia y efectividad de las IES públicas o privadas, en particular en casos de anomalías graves, y iv) la norma estaría acorde con los cambios institucionales y jurídicos requeridos por el TLC, la OCDE, el Banco Mundial y el FMI de crear tanto mercado como sea posible y tanto Estado como sea necesario.

En todo caso, el debate sigue abierto respecto a los alcances y las limitaciones que tiene la norma vigente. Ella se determina, como toda política pública, en una discusión de narrativas, soluciones, problemas y oportunidades que definen el flujo o margen de decisión de las autoridades gubernamentales.

Como bien se ha observado en el texto, la autonomía universitaria posee unos rasgos distintivos que se han materializado luego de diversas sentencias constitucionales y demás normas que han modulado los alcances y las limitaciones del concepto. En todo caso, a juicio de los autores, es necesario seguir vinculando a los actores estratégicos de la educación superior al debate público sobre nuevos retos y consideraciones sobre esta materia en los años venideros.

La universidad debe ser una institución autónoma creadora de conocimiento, articuladora de la investigación, la docencia y la extensión encargada de la difusión, el ejercicio humanista y el interés público. Es, en esencia, un espacio de encuentro pluralista, respetuoso de ideas, con el fin de contribuir a la transformación del país, pero para alcanzarlo, es necesario que sea independiente y respetada por el Estado, por lo que hay que impedir todo intento estatal de socavar la libertad universitaria y la autonomía.

La educación superior es un bien público y es un derecho fundamental que el Estado debe garantizar a la sociedad mediante políticas públicas en las que el constante monitoreo de los actores involucrados sea un requisito indispensable para su mejoramiento y protección.

\section{Referencias}

Cerebeiros Álvarez, Eduardo. "La licentia docendi: comienzo y desarrollo de la carrera universitaria”. Repositorio Universidade Coruña, núm. 8 (2004): 259-279. https://ruc. udc.es/dspace/bitstream/handle/2183/2316/AD-8-15.pdf?sequence=1\&isAllowed=y (acceso septiembre 14, 2018). 
Colombia, Corte Constitucional. Sentencia C-544 de 1 de octubre de 1992. M. P. Alejandro Martínez.

Colombia, Corte Constitucional. Sentencia T-002 de 8 de mayo de 1992. M. P. Alejandro Martínez Caballero.

Colombia, Corte Constitucional. Sentencia T-406 de 5 de junio de 1992. M. P. Ciro Angarita Barón.

Colombia, Corte Constitucional. Sentencia T-492 de 2 de mayo de 1992. M. P. José Gregorio Hernández Galindo.

Colombia, Corte Constitucional. Sentencia T-574 de 10 de diciembre de 1993. M. P. Eduardo Cifuentes Muñoz.

Congreso de la República de Colombia. Ley 30 de 1992, "Por la cual se organiza el servicio público de la educación superior". Bogotá: Diario Oficial No. 40.700, 29 de diciembre de 1992.

Consejo Nacional de Acreditación. “¿Qué significa calidad en la educación superior? ¿Cómo se determina?”. https://www.cna.gov.co/1741/article-187264.html (acceso septiembre 1, 2018).

Fassó, Guido. Historia de la filosofía del derecho, tomo 2: La Edad Moderna. Traducido por José F. Lorca Navarrete. Madrid: Pirámide SA, 1982.

García Enterría, Eduardo. "La autonomía universitaria", Revista de Administración Pública, núm 117 (1988): 7-22.

Keynes, Jhon. El fin del dejar hacer. Madrid: Ariel, 1970.

Ministerio de Educación Nacional. Educación de calidad, el camino para la prosperidad. Bogotá: Autor, 2016.

Organización para la cooperación y el desarrollo económicos [OCDE]. Report on Benchmarking Higher Education System Performance: Conceptual Framework and Data. París: Autor, 2017.

Pavón Romero, Armando y Clara Inés Ramírez. "La autonomía universitaria, una historia de siglos". La autonomía universitaria, una historia de siglos 1, núm. 1 (mayo 2010): 157-161. https://www.ries.universia.unam.mx/index.php/ries/article/view/22/84, (acceso agosto 5, 2018).

Petrella, Ricardo. Los limites de la competitividad. Buenos Aires: Sudamericana, 1996.

República de Colombia. Constitución Política. Bogotá: Legis, 1991.

Universidad Distrital Francisco José de Caldas. "Panel: La crisis de las universidades públicas en Colombia”. https://www.udistrital.edu.co/panel-crisis-las-universidades-publicas-en-colombia (acceso septiembre 1, 2018). 